\title{
FEMINISM AND THE LITERATURE \\ OF PRAMOEDYA ANANTA TOER
}

\author{
女性主义与普拉穆迪亚・阿南达・杜尔的文学创作 \\ Cendrawaty Tjong \\ Chinese Department, Faculty of Humanities, Bina Nusantara University \\ Jln. Kemanggisan Ilir III No. 45, Kemanggisan - Palmerah, Jakarta 11480 \\ cencen_zzz@yahoo.com
}

\begin{abstract}
Feminism refers to the social ideological trends that women ask for equal rights as well as the results of ideology when women know the world, the ego, and the sexual relationship in their process of seeking self-liberation. This paper starts with describing the periods in which Indonesian women acknowledged and was associated with western feminism as well as analyzing its period of development. This paper aims at researching the feminism idelology of Pramoedya Ananta Toer, a leading Indonesian writer, including the factors which affect his opinion on women and the expression of his feminism, which is richly displayed throughout his works. The finding of this research shows that in Pramoedya Ananta Toer's perspective, equality between men and women is manifested in the partnership between men and women, that this partnership is applied in every aspect of lives, which is advanced-throught in Indonesian's patriarchal society.
\end{abstract}

Keywords: feminism, women movement, Indonesian, Pramoedya Ananta Toer

\section{摘要}

女性主义是泛指妇女要求平等权利的社会思潮, 是妇女在寻求自我解放的过程中,认识了世界、认识了 自我、认识了两性关系的一种认识成果和思想结晶。本文首先叙述印尼接受西方女性主义的过程, 在此为背景 下, 探讨了印尼著名作家一一普拉穆迪亚・阿南达・杜尔的女性主义思想及其作品中的表现。根据普拉穆迪亚小 说里的观点, 所谓的男女平等就是男性和女性在生活的任何方面都是合作的伙伴, 这种看法当时在父权制的印尼 社会中确实是很先进的。

关键词: 女性主义、女性运动、印尼、普拉穆迪亚 
前言

普拉穆迪亚・阿南达・杜尔（1925一2006）生 于中爪哇小镇布洛拉, 是印尼著名的作家。他的生活 多数在监牢度过: 荷兰殖民时期, 他被关进三年监 牢; 印尼旧秩序政府时期因他写了《印尼华侨》被政 府逮捕，坐了一年的监牢; 1965年九・三0事件后以共 产主义者的罪犯被苏哈托政府逮捕, 没有经过法律审 判就被抓进监牢并流放了14年, 直到1979年12月才被 释放; 释放后还被国家软禁, 1999年才被印尼政府完 全释放、洗清罪名, 得到平反并获得人生自由。

黑暗的人生历程以及艰苦的监牢生活并没有磨 灭他的写作能力, 反而磨练了他的人生经验, 使他写出 许多作品, 最优秀的代表作一一《四部曲》经过了多 次烧毁才创造出来的。作为作家, 他在印尼没有什么 地位, 一直以来没有被印尼政府与文学界重视。他被 称为 “左翼文学家”、“共产主义文学家”。1979年 虽然他被政府释放, 但在印尼失去了言论自由、公民 权利等社会活动。虽然如此, 他在国际上是位有知名 度的作家。他的作品被翻译成39多种语言, 多次获诺 贝尔文学奖提名。从1988年至 2005 年, 他获得了很多 国际奖。美国康奈尔大学教授安德生 (Ben Anderson) 誉之为“东南亚在世的最伟大作家。”1995年普拉 姆迪亚获得菲律宾文学奖, 这引起了印尼文学界的轰 动。26个印尼文学家以及文化文人提出强烈的抗议, 逼迫菲律宾文学基金会取消他们做出的决定, 因为他 们认为普拉姆迪亚曾是印尼人民文化协会为代表的左 翼文化机构的相关人物, 因此不值得获得此奖。

普拉姆迪亚一生中创作了50多种作品，包括小 说、短篇小说、散文和评论。笔者发现他的作品都表 现了丰富的女性主义思想。普拉姆迪亚的作品里所涉 及到的女性都表现出勇敢与战斗的精神。这表明普拉 姆迪亚非常赞同与支持印尼妇女为争取男女平等而斗 争。在普拉姆迪亚时代, 这些观点是非常独特和新颖 的, 而在目前的印尼社会, 还有很多妇女都受到歧视 和虐待, 可见部分的印尼妇女还不能摆脱父权式的社 会制度。普拉姆迪亚的女性观却能给印尼妇女带来一 个新的看法和思考。本文视图通过分析普拉姆迪亚代 表作对此加以阐述，给读者提供一些参考资料。

内容与分析

世界各国女性主义和妇女运动并不是孤立的” 印尼也是如此, 它的女性运动及女性思想跟当时的世 界思潮存在密切的关系。西方女性主义在世界妇女解 放中起了启蒙和推动作用, 西方女性运动浪潮大大地 影响了印尼的妇女运动。

女性主义或女权主义这个词最早出现在法国, 意味着妇女解放。它后来传到英国和美国, 逐渐流行 起来。女权主义是泛指妇女要求平等权利的社会思 潮。女权主义又称 “男女平等主义” 或 “男女平权主 义。” 女权主义又称 “女权运动”, 是资本主义国家 妇女在经济、社会、文化、政治等各个领域争取男女 平等, 争取从根本上改变妇女社会地位和社会作用的 一种理论与运动。在西方, 女权运动最初是追求男女 平等, 指争取教育平等和政治上的平等, 尤其是争取选 举权。后来, 女权主义者开始意识到男女不平等的原 因是因为性别的因素, 所以女权运动变成分析男女为 何不平等, 审视男女的权利架构, 强调性别分析, 因此 它不但包括女权问题, 也包括性别分别问题, 就是反对 包括性别歧视在内的一切不平等。
女性主义产生的背景

女性主义的产生与父系社会有密切的联系。世 界上大多数文化都存在男人胜于女人、男人比女人 重要的支配性观念, 因此女人一般被认为是男人的奴 隶、生孩子的工具、满足男人性爱的器而。历史女人 屡屡成为政治上的牺牲品。她们没有地位和权利, 可 以被男人送来送去, 也可以被男人卖出去。

这样的歧视源于特定文化背景。很多国家的 父系社会把《圣经・创世纪》当作男人高于女人的依 据。《圣经・创世纪》第2 章22-23节写道: “耶和华 神就用那人 (指 “亚当”) 身上所取得筋骨造成一个女 人, 领她到那人跟前。那人说: “这是我骨中的骨, 肉 中的肉, 可以称她为女人, 因此她是从男人身上取出 来的。”女人后来也成为男人的灾难, 《圣经・创世 纪》第三章讲的是女人首次违背上帝禁令吃了智慧之 果, 然后劝男人也尝一尝, 导致男人犯罪, 从此上帝与 人类永远隔离。由于女人犯了吃那智慧之果的原罪,

《圣经・创世纪》第3 章16节说明上帝惩罚女人: “我 必多多增你怀胎的苦楚, 你生产儿女必多受苦楚。你 必恋慕你丈夫，你丈夫必管辖你。” 《圣经》里上帝 要男人管辖女人的这个惩罚成为基督教社会世世代代 的依据。除了《圣经》以外, 还有其它经典也提到男 人比女人重要或好于女人的依据, 如: 伊斯兰教的《 古兰经》第4章 “7世纪”里写着：“男人掌管女人, 因 为真主把他们中的一个造得比另一个更好, 因为男人 用财产供养女人，所以女人是应该驯阴及的。”; 古 罗马法中有这样一条文：“女人由于心性轻浮, 即使长 大成人也要有人监护。”(《12法典》) (啜, 2005)

印尼社会是个父系社会, 也是个重视宗教的国 家。人民认为理性、逻辑、智力、主动、高贵都代 表男人; 而混乱的情感!无法控制的性欲、被动、野 心、下贱都是代表女人。社会里两性不平等以及不公 平的态度和思想一直以来都成为女性主义的斗争对 象, 也是女性主义产生的背景。

\section{女性主义在印尼的传播和影响}

西方占领了印尼四百多年，在这四百多年里， 印尼经济、社会都受到了西方资本主义、殖民主义 的影响。18-19世纪的西方大型地出现女权主义的浪 潮。西方妇女通过女性运动争取选举权、受教育权、 就业权等。到了 20 世纪60年代西方的女性运动注重于 追求妇女解放和自由、反对传统的男女不平等和男性 对女性的歧视和奴役, 改变妇女的地位。

印尼作为西方统治的殖民地之一，也难免不受 西方妇女潮流的影响。印尼女性运动和解放思想都离 不开卡尔蒂妮，她被印尼社会称为女性解放之母，后 来也成为印尼妇女的一个典范。卡尔蒂妮被列为印尼 女性解放的先驱, 她一直努力地引导着印尼妇女冲出 封建专制的牢笼, 逐步走向妇女解放的道路。卡尔蒂 妮接受到荷兰教育，常接触荷兰早期女性主义者的想 法并加以讨论。她和斯德拉・基韩德拉小姐四年的沟 通期间，常交换妇女运动的一些意见。斯德拉・基韩 德拉小姐是个社会主义积极分子，她争取工人阶级的 教育权, 也主张帮助妇女摆脱封建的婚姻制。她和卡 尔蒂妮的友谊, 再加上卡尔蒂妮阅读过很多书籍, 尤 其是阅读那些与女性解放有关的书籍, 给卡尔蒂妮很 大的影响, 使她思考印尼妇女的情况, 盼望着印尼妇 女的解放, 不受任何束缚, 可以走出家庭的牢笼, 她 也通过她看到的妇女情况和自己的经验体会印尼妇女 不平等的地位，最后她认为印尼妇女应获得与男性同 等的机会, 争取教育权等权利。卡蒂妮的早期女性主 义思想表现在几个方面：一、她非常盼望妇女可以独 
立。1899年5月25日她给斯德拉・基韩德拉小姐的信中 写道: “我非常想认识一个我仰慕的妇女, 他独立及 自信、活泼及坚强, 她不只为自己工作, 也为社会工 作, 给人类带来一些幸福。想起那个时代, 我就热血 沸腾。”（Pane, A. , 2005: 写给Miss. Zeehandelaar 1899年5月25日的信）；二、卡尔蒂尼赞同自由主义 女性主义争取与男性同等的教育权。她给斯德拉 - 基 韩德拉小姐1899年5月25日的信中表述这个问题：“我 们妇女还被旧封建思想捆牢着, 只有少数妇女才能享 教育。”; 三、卡尔蒂尼反对社会对妇女的歧视, 她 要求男女都能受到公平的待遇。1900年8月23日她给 斯德拉・基韩德拉小姐的信中写着: “我要生男孩儿, 也要生女孩儿, 我会公平地教育他们, 除掉那些重男 轻女的习俗。男人从小受宠爱, 他们从小受到的教育 是歧视女人地位的教育。我要同等地教育我的孩子, 不分男女, 而且要教他们不可歧视对方! 要互相尊敬 彼此。我要删除男女的界限, 因为人类是同等的。”

; 四、卡尔蒂尼看不惯 “一夫多妻” 的婚姻制, 她也 要求婚姻关系中的男女要平等。1900年8月23日她给 斯德拉・基韩德拉小姐的信中写着：“上帝创造女人成 为男人的同伴。女人的幸福是可以与丈夫共度平安和 同等的婚姻。但是, 如果我们的宗教允许男人拥有很 多妻子，那么这样的同等婚姻如何达到呢?”

据阿利维亚的看法, 以卡尔蒂尼争取的妇女权 利的印尼女性主义比较适合归纳为自由女性主义。但 是, 卡尔蒂尼也认为, 争取妇女的解放不只是妇女的任 务, 也属于男性的任务。印尼人民不能进步, 如果女 性落在后边的话。女性的进步是提高印尼社会的地 位, 男性不是女性的敌人, 而是女性的工作伙伴, 因 此女性也应该完成当母亲的任务。

20 世纪中期至六五年九 -三 0 事件前是印尼社 会组织的发展时期。20世纪初至20年代女性会议受 到卡尔蒂尼思想的启发, 因此这时期的女性思想体 现出卡尔蒂尼自由女性主义思想。从 20 年代末至六 五年九 -三 0 事件前, 印尼女性主义开始趋向于社会 主义。20年代女性主义的代表人物是苏卡俄西 $\left(\mathrm{Su}^{-}\right.$ kaesih) 和姆纳西亚(Munasiah) 等。姆纳西亚在三宝 垄的女性运动会议表示: “以前妇女是家庭的太阳， 但是现在妇女是资本主义的工具。其实妇女自古以 来川流不息地反抗, 但还是受压迫。如今出现了很 多妓女, 这是谁的错? 这就是资本主义和帝国主义的 错！（Acehmarxist, 2007）她们这些看法受到了荷 兰共产主义者一一斯内夫利特(Hendricus Jose Phus Franciscus Mariesneevhet) 的反资本主义的影响。 她们认为女性受压迫与资本主义剥削劳动有关, 因此 女性的真正敌人是资本主义。30年代初苏加诺在他政 治生涯中开始接触了马克思主义, 因此对他来说, 印 尼女性主义应该偏向于社会主义。他强调印尼妇女只 谈男女平等是不足的, 打倒资本主义才是当务之急 (Arivia, 2001)。印尼独立以后至六五年九・三0事 件前, 印尼出现了很多妇女组织, 这些妇女组织有的偏 向卡尔蒂尼自由女性主义思想, 有的偏向于激进女性 主义思想, 也有的认为女性思想应该回到伊斯兰教女 性思想, 但更多的是偏向社会主义的女性思想, 因为当 时阁尔瓦妮成为当时最大和富有影响力的女性组织。 她们支持苏加诺, 认为苏加诺对于女性的任务的看法 是正确的。

六五年九・三0事件后女性思想被控制, 政府创 造了一个 “母亲主义” 女性思想, 此女性思想把印尼 古代封建思想、伊斯兰教和爪哇思想混合起来, 创造 符合印尼的女性形象, 认为女性形象的定义是有道德 修养、相信宗教、能装饰自己、服从男性、听从命
运、不爱说话等的女性形象。这时期激进主义女性运 动已经不存在了, 女性的身体成为政府的商品也成为 商业的商品, 女性也成为男人性欲的对象, 建设国家 的机器人、权力的牺牲品。这时期的妇女组织只有女 性的聚集活动, 并没有商讨全国各个阶层妇女面临 的问题 (妇女强暴、就业问题、拐卖妇女与未成年人 等), 而且妇女组织里的妇女职位取决于她丈夫在政 治上的地位和权力, 丈夫的权力和地位越高, 妻子在 妇女组织的任务的职位越高, 因此这时期的妇女被男 性控制、失去了原有的权利, 也是妇女落后的一个时 期。98年印尼暴乱, 政府没有立即帮助那些受害的妇 女, 这种歧视引起社会上的震怒, 导致新的妇女民族 改革。前任总统苏哈托下台后, 随着外国女性思想的 传入, 印尼女性主义摆脱母亲女性主义思想, 出现了 很多新趋向, 如激进女性主义、后殖民女性主义、环 境女性主义、后现代女性主义等。这时期也出现了很 多妇女组织, 妇女们重新进入社会和政治舞台, 争取 她们在苏哈托政府前拥有过的或目前该拥有的权利。

她们对国外的女性主义思想加以思考，提倡妇女应该 从苏哈托政府创造的母亲主义解放出来, 创造出一个 更符合本国国情、历史和文化背景的女性主义。阿利 维亚及其他女性主义者表示目前妇女的压迫不仅是因 为文化和父权制或男权制，而且也因为全球商业化、 新资产主义、新帝国主义和消费主义的扩张, 因此印 尼目前的女性主义应该主张妇女关注话语, 让话语成 为妇女的权力, 妇女也要自由做主、自由作决定, 妇 女解放是女性和男性共同合作摆脱新帝国主义的压 迫。不能否认, 人们对某种事情的观点是受到环境 (文 化、历史、政治) 影响的, 普拉姆迪亚的女性主义也 是如此。在印尼女性主义特定的历史文化背景下, 产 生了他自己的女性主义。下文就是笔者对普拉姆迪亚 的女性主义的分析。

\section{普拉姆迪亚对女性主义的接受}

普拉姆迪亚的小说大部分写那些受到殖民主 义、帝国主义、爪哇封建主义、资本主义压迫的普通 老百姓。他的小说里也提到各种各样的奋斗妇女, 而 且这些奋斗都是失败的。普拉姆迪亚也常提到民族 革命的观点, 他认为印尼的革命或独立斗争必须也包 括资产阶级革命、社会主义革命和反封建! 反殖民的 斗争。他认为只有基层人民组织起来才能完成这场革 命。通过阅读及查询一些参考文献, 笔者发现普拉姆 迪亚的女性主义思想受到几个方面的影响:

\section{一、普拉姆迪亚母亲、父亲和外婆的影响}

普拉姆迪亚的父母支持前总统苏加诺的民族革 命, 他父亲也是前总统苏加诺组织的社团的积极分子, 除此之外, 他父亲也是民族教育的积极分子。他父亲 接受民族主义左派反殖民主义的思想, 认为无产阶级 才是国家的栋梁。后来他母亲也受丈夫的影响, 全心 支持她丈夫, 变成其中一个女性运动积极分子。那时 候这些民族活动受到荷兰政府严格的监督普拉姆迪亚 的父亲也为此失去供养家庭的可能, 过着贫困的生 活。为了生计, 普拉姆迪亚的父亲终于再次进入荷兰 政府学校教书, 这个决定使全家人失望。普拉姆迪亚 的父亲承受不了如此打击, 便走进奢场, 整天都在那 儿混生活, 因此全家的经济都落在普拉姆迪亚母亲的 肩上。

笔者认为普拉姆迪亚的女性思想最初受到他小 时候家庭的影响, 而这个家庭的影响可以表现于三个 方面: 
第一、普拉姆迪亚在每次访问都会提到他母 亲, 由此可见, 母亲对他小时候的影响很大。如: 普拉 姆迪亚1991年7月26日在接受KeesSnoek (荷兰人) 的采 访时,

说: “我母亲是个理想的母亲, 我这样说不是 因为她是我的母亲, 但是我越来越想念她所作所为。 我非常尊重她的教导, 她说过: “要成为自己的主人, 拼命地干活, 享受自己劳动的成果。如果你长大了, 就 去欧洲留学。, 我17岁之前每天下午都去放牧, 碰到 了荷兰政府的学生时, 他们一定取笑我, 我就因放牧 而觉得差耻。有一次我向母亲诉说我的感情, 母亲便 批评我, 说: “应该差耻的不是你, 而是他们, 因为他 们怕劳动。劳动才是光荣, 谁不敢劳动就是无耻。

(Boef\&Snoek, 2008:112-113)

普拉姆迪亚母亲对他生活上的影响, 特别在评 价妇女的标准上。她视劳动为荣耀, 不管在贫困还是 艰难的情景下都不恳求别人的怜悯。她主张只有拼命 地干活, 才能享受劳动的成果。母亲的这些看法使他 认为女性不应该只依赖以男性, 女性也应该劳动, 要 为前进奋斗, 但最重要的是她也能吃苦。她的母亲希 望她的孩子们能够去欧洲追求更高的学问。普拉姆迪 亚曾提过, 他把印尼的革命比成女性的身体, 特别是 他母亲的身体。普拉姆迪亚母亲的性格很坚强但身体 很脆弱, 不过她脆弱的身体从不扑灭她奋斗的精神, 也没有阻碍她参与各种各样活动的精神。

第二、普拉姆迪亚多次提到母亲对他的重要 性, 使大家都认为普拉姆迪亚的女性主义思想是因为 他受到了母亲的影响, 不过笔者认为如果说普拉姆迪 亚的女性思想只受到他母亲的影响, 这不能说完全 正确的, 没有他父亲早期的影响, 就没有完整的普拉 姆迪亚女性思想。普拉姆迪亚提到, 他父亲的爱国精 神和反殖民主义精神曾使他成为普拉姆迪亚生活上最 爱慕的父亲, 但自从父亲因经济危机而回到荷兰政府 学校教书后, 他开始觉得父亲背叛了他的梦想, 从此对 父亲失望。除此之外, 普拉姆迪亚也提到：“他父亲是 个坚固及勇敢的男人, 他充满了梦想和前进的想法, 敢为其梦想奋斗。他为了让印尼人民获得同等的教育 权, 不堪牺牲自己或家庭。可惜的是, 在面对挫折的时 候, 他就轻而放弃。他父亲也是个文学创作者, 是个自 由主义的爪哇人, 他不做宗教礼拜, 爱慕爪哇文化, 厌恨封建主义，但不知不觉也支持爪哇封建主义。

（Teeuw, 1997:10）虽然普拉姆迪亚对父亲失望, 但普 拉姆迪亚也承认, 他的尖锐的民族意识、对一切不公 平事物的奋斗精神、对爪哇社会的一切看法及把教育 成为建设国家和解放人民的一切看法都是因为受到父 亲的影响。普拉姆迪亚父亲把无产阶级成为国家栋梁 的看法加上他反殖本主义和封建主义的精神, 都给青 年时期的普拉姆迪亚一定的影响。

第三、除了父母的影响，普拉姆迪亚也受到他 外婆的影响。普拉姆迪亚提到, 他外婆是个活泼、耐 心、不轻易放弃、勤奋和真正的劳动者。她意识到 她的地位比她的丈夫和孩子低, 甚至没有与她的女婿 讲过话。虽然她生活很穷, 但她从不向女儿和女婿追 求过什么, 探访孙子们时, 总是带着小礼物给孙子们 并宠爱他们, 对普拉姆迪亚来说, 除了母亲以外, 外 婆也是他最爱的女人（Teeuw, 1997:14）。笔者认为, 普拉姆迪亚外婆对他的影响也体现在他反爪哇主义的 态度。普拉姆迪亚外婆成为爪哇封建主义的牺牲品, 普拉姆迪亚把危害人民的爪哇封建主义称为 “爪哇主 义”, 就是对上司忠心耿耿! 盲目地服从比我们地位高 的人。普拉姆迪亚也认为爪哇语或爪哇文化的烙印, 存在上级和下级、贵族和平民等方面的鸿沟, 就是爪
哇主义的缘故, 印尼人民才解放不了, 从古代到现代一 直被侵略。

从上文, 我们可以看出普拉姆迪亚父母和外婆 对他年轻时的影响, 这些影响坚定他后来的思想, 除了 坚定了他的社会主义现实主义, 也坚定了他的女性思 想。

二、高尔基作品：《母亲》及其他文学作品的影响

普拉姆迪亚小学毕业后, 经过母亲的同意, 去 汭水市广播学院读书。这时期他开始接触很多文学作 品, 如: 奥诺雷・德・巴尔扎克 (Honore de Balzac) 和 埃米尔・左拉 (Emile Zola) 的作品, 爪哇的心灵书,

《De Laatste Stuiptrekkingen》(描写反英国帝国 主义的战争) 等。这些书对他以后的文学创作有一定 的影响, 使他的创作都取材于现实生活。后来, 他去 日本帝国主义政府承认的中学上课, 这时期他接触了 穆哈玛・哈大写的希腊哲学, 打开了他对理智的理解, 他说：“从那段时刻起, 我开始抬高人类的理智。”

(Teeuw, 1997:17)

普拉姆迪亚1991年7月26日在接受Kees Snoek ( 荷兰人) 的采访时也提到：“我最喜欢的作者是约 翰・恩斯特・斯坦贝克 (John Steinbeck), 我翻阅了 他的作品《人与鼠》, 对他写实的文学手法表示衷 心的钦佩。我也喜欢安东民德圣-埃克苏佩里 $\left(\mathrm{An}^{-}\right.$ thony de Saint Exupery)描述人类在自然的存在, 他把人类描述为大自然里巨大力量, 但成为个人 的存在, 这个力量是渺小的。”普拉姆迪亚从芬兰 作者Lode Zielens学到 “思想与现实没有分隔” 的想法; 他从马克西姆・高尔基 (Maxim Gorky) 那儿学到 “人类应该知道他们的历史” 的思想。

(Boef\&Snoek, 2008:169-170)

1955年普拉姆迪亚翻译了高尔基的《母亲》。 在翻译过程中, 普拉姆迪亚开始对高尔基的社会主 义现实主义引起了兴趣。后来, 这部作品启发了普拉 姆迪亚, 写了《印尼文学与社会主义现实主义理论》, 认为文学是消除殖民主义、帝国主义和资本主义的主 要工具，它应该为人民群众服务，而不是为贵族或资 产阶级服务, 除此之外, 作家要从现实的革命发展中真 实地、历史具体地去描述现实, 作品描写的真实性和 历史具体性必须与用社会主义精神从思想上改造和教 育劳动人民的任务结合起来。高尔基的《母亲》给普 拉姆迪亚个人带来其它的意义, 就是: “把最高的荣 耀赐给世人从来不知道尊敬的母亲。”普拉姆迪亚把 高尔基的写作方式比喻成 “某个人拿着房柱摇动, 使 整个房子都动摇了。” 高尔基描写的母亲是个生活在 20 世纪初俄国民族革命时期的一个妇女，她支持并帮 助她孩子和他的朋友们同资本主义斗争, 成为一个为 社会主义而奋斗的无产阶级革命者的英雄形象” 高尔 基描所创造的母亲的形象，给普拉姆迪亚后来创造四 部曲的温托索罗姨娘 (Nyai Ontosoroh) 的形象起了 启发作用。普拉姆迪亚对温托索罗姨娘的奋斗表示 敬佩。他通过故事里所发生的事件, 也通过故事的主 人公, 一个名叫 “明克” 的爪哇族知识分子的个人对 话, 述说了普拉姆迪亚对女性的一些想法, 如: 父权 制、爪哇封建主义、殖民主义、资本主义和种族主义 是女性受压迫的因素, 因此妇女若要解放就应该与父 权制、爪哇封建主义、殖民主义、资本主义和种族主 义的一切不公平制度而奋斗，但这些奋斗应该是女性 和男性共同努力。

除了以上文学作品外, 普拉姆迪亚也很敬佩卡 尔蒂尼的奋斗和女性思想。他阅读卡尔蒂尼的书信、 阅读荷兰有关女性解放和女性主义的小说: 钟女士 (C. 
Goekoop de Jong)的 《Hilda van Suylenburg》和 荷兰社会女性主义胡根 (Cornelie Lydie Huygens) 的 《Barthold Meryan》, 并通过这两个小说去批评卡尔 蒂尼的女性解放, 认为只有革命才能推翻旧制度, 改 为新制度 (Toer, 2007：169)。他评价卡尔蒂尼的女性 解放的时候, 也提到卡尔蒂尼不仅是印尼妇女解放的 先锋, 也是爪哇封建主义的批评者和反抗者, 是印尼 现当代历史的起源。

\section{三、印尼前总统苏加诺的影响}

印尼前总统苏加诺是普拉姆迪亚最敬佩第二个 人物, 普拉姆迪亚接受男性杂志采访时说：“自从前总 统苏加诺下台以后, 印尼到目前为此都还没出现真正 的领导。前总统苏加诺是印尼领导的榜样, 他掌握各 个方面的知识, 如: 文化、政治、历史、地理等, 现在 还没有领导在知识方面模仿前总统苏加诺。他是我理 想的领导形象。” 前总统苏加诺是普拉姆迪亚偶像 之一, 他非常尊重他” 前总统苏加诺曾说过: “人民 大众必须参与民族革命才能改变国家, 不要看轻人民 大众, 因为他们才是改革的中心力量。”普拉姆迪 亚一定比任何人理解前总统苏加诺的话语, 因为后来 他把人民大众现实的生活都表现在他的作品中。前总 统苏加诺非常支持女性争取她们的妇女权力, 但是他 强调如果妇女单单争取男女平等是不足的, 她们也必 须打倒资本主义, 因此前总统苏加诺非常支持妇女参 政。阁尔瓦妮成为印尼独立后最大的妇女组织, 除了 争取妇女在各个方面的权利 (教育权、政治权、婚姻 权、就业权等), 也支持印尼独立、反殖民主义和帝国 主义。前总统苏加诺偏爱这个无产阶级的代表团, 认 为它才是真正的妇女组织, 那时候出现的其他妇女组 织都被前总统苏加诺批评为贵族妇女组织。没有任何 书籍提到前总统苏加诺对女性运动思想影响到普拉姆 迪亚的女性思想。普拉姆迪亚只有多次提到他非常尊 敬苏加诺的思想, 认为苏加诺的思想是正确的。笔者 认为以普拉姆迪亚对前总统苏加诺的爱慕和尊敬为根 据, 不妨说他也受到苏加诺的女性思想的影响, 再 说, 我们在普拉姆迪亚的四部曲里对洪山梅的描述可 以体会到 “妇女必须参政” 的女性思想博得普拉姆迪 亚高度赞赏。

笔者认为普拉姆迪亚的女性主义受到的以上三 方面影响是互相联系的, 互不分隔, 形成了普拉姆迪 亚女性思想的整体性。母亲成为他评价其他女性的标 准; 父亲鼓励他对社会上所有不公平的一切而进行奋 斗; 外婆的遭遇影响他对爪哇封建主义的看法; 在翻 译高尔基的《母亲》的过程中，他奠定了社会主义现 实主义的文学理论; 普拉姆迪亚对前总统苏加诺的爱 慕和尊敬, 使之接受了他的妇女观。

\section{普拉姆迪亚作品中的女性主义}

“没有妇女就没有人类; 没有人类就没有人赞 美上帝。妇女生育时喊出的声音、流出的血和汗就是 唯一赞美上帝的理由。” (明克, 《足迹》430页)

普拉姆迪亚的作品提到很多女人的命运与奋 斗。她们向殖民主义、资本主义和爪哇封建主义而展 开斗争。当笔者阅读普拉姆迪亚的作品时, 感觉到普 拉姆迪亚的经历、思想等深深地表现在他的作品中和 他创作的人物思想中。他的代表作一一布鲁岛四部 曲, 使读者进入了一个真实的历史背景, 感受到人物的 情景变化和人物的互相矛盾；他创作的《海女儿》

《密达一一可爱的金牙小姐》、《拉拉萨蒂》、《万 登南部发生的事件》都表现出对被侮辱、被损害的小 人物和妇女的极大同情。这些作品描述妇女所面对的
问题, 提出他对妇女命运的感受、看法和思想。笔者 认为普拉姆迪亚提出的女男不平等的问题到现在为止 都仍然存在社会中。妇女的社会地位非常低, 我们可 以从普拉姆迪亚作品中看到这个问题:

\section{一、女性被社会视为弱者, 而男性被社会视为强者的} 情景

由于女性的社会形象常常被视为弱者，因此男 性在任何方面都被社会认为比女性更有用。波伏瓦 在《第二性》中分析了女性是男性的 “他者” 的处 境, 认为:女性的特征都是社会造成的, 女性并不是 生而为女性，而是逐渐形成的。她指出女人因为体力 较差, 当生活需要体力时, 女人自觉是弱者, 男人用 法律形式把女人的低等地位固定下来, 而女人还是甘 心服从。这 “他者” 的处境使妇女被视为社会上的弱 者。普拉姆迪亚的《万国之子》第15章讲述了这个问 题: 阿章 (华桥富翁) 想霸占温托索罗姨娘的财产, 他想 了狡猾的计划, 利用美人计, 劝罗伯特 (温托索罗姨娘 的长子)利用一切手段争夺温托索罗姨娘的财产. 罗伯 特认为这计划万不可行, 因为他还有一个妹妹, 但阿章 便说：“一个妹妹, 也值得那么愁眉不展么?; 您妹妹 不过是个女子。您妈妈不过是个土著妇女。对您来 说, 她们有什么力量? 她们无能为力。少爷, 女流 之辈就像脆弱的香蕉树杆, 不堪一击。我说您是唯一 继承人, 言下之意, 她们俩都不在话下, 就跟没有她们 一样。”此观点也在《拉拉萨蒂》里表现出。拉拉 萨蒂对她生为女人感到很遗憾。她看到荷兰殖民政 府对待他们占领的地区的人民, 就觉得很生气。她 想: “如果我是男子, 我会做很多事, 如果我是男子, 我也即将烧毁这个荷兰殖民政府占领的地区。”拉拉 萨蒂后来想领导人民向荷兰殖民者奋斗, 但她母亲对 她说: “你应该即刻离开这个地区, 你若呆在这里就会 不幸, 而且将危害其他人。你只是个弱女子, 也没有什 么武器, 你不可能带领这里的人奋斗。”(117页)

普拉姆迪亚通过他小说里的人物对话, 来描述 社会上把妇女视为弱者而男子却被视为强者、战斗 者的状况, 所以男子若知道女子比他强, 他的心就觉 得不安、不服。《万登部发生的事件》120页就提表 现出此观念：村长计划农民的妻子们都学认字, 但这 个计划轰动全村, 到处都听到不满的尖叫声。有农民 说：“我不能认字, 难道我妻子就会认字?”; 又有人 说: “女人比男人聪明, 成何体统?”; 《玻璃屋》 里也提到这个问题。小说里提到西蒂・苏达利是第一 个敢在公众面前说话的女人, 她也领导人们向荷兰殖 民主义反抗。她比卡尔蒂尼更先进。可是伊斯兰教领 导们都认为她与妓女没有什么区别, 她这样做是一种 卖身体的行为。她虽然很漂亮, 也很有鬼力, 但如果 一个女人没有当妻子的条件, 漂亮和鬼米力又有何用处? ; 知识分子也觉得她是丈夫所害怕的典型妇女, 他们 说: “哪有男子敢娶学识高的女子?”（《玻璃屋》 : 374和406页)

\section{二、女性常成为男性的工具和他们的性机器}

由于妇女被社会视为弱者, 因此妇女常受到男 性的侮辱并往往被他们任意对待。此观点也可以从普 拉姆迪亚的作品《人世间》里看到: 温托索罗 (或萨妮 庚) 的父亲为了得到高的职位, 把萨妮庚卖给荷兰人。 那个荷兰人得到了温托索罗，心里很高兴。他把萨妮 庚待为他的娃娃似的。萨尼庚说：“他把我抛向空中， 又用手从腰间把我按住, 使劲地摇晃着我, 这使我稍 微清醒一点。他又把我站在地板上。我仍然站不稳。 他用双手保护我, 不让我择倒。我摇晃了一阵子, 最 
后还是栽倒在床沿上了（92页）。”后来温托索罗姨 娘说:

当别人的姨娘, 生活很辛酸的。她是卖给别人 的家奴, 义务是满足主人的欲望，什么事情都得顺从 她的主人。她必须随时提防发生种种可能: 主人把她 玩够了, 玩淢了, 说不定哪一天会把她和她生下的孩子 一起赶走。因为不是正式婚姻, 生下的子女在土著民 中也被人瞧不起（94页）。

普拉姆迪亚也通过密达的对话提到女人只有成 为男人发泄兽欲的玩物。密达认为: 男性如果对女人 存在什么目的, 他就会变成绵羊似的, 他们这样做是 为了发泄他们的兽欲。密达很爱阿玛, 可是阿玛只 把密达当为他的性机器。当他知道密达怀孕了, 就说 密达因想结婚而骗了他。他对密达说, 他是不可能 娶她的, 因为他怕被社会对他的批判。（参考于《迷 达一一可爱的金牙小姐》，92-93页）

三、如果有什么不吉利的事发生, 女性就成为社会的 替罪羊

如果她们的行为有什么不端就认为她们是下贱 的女人, 使全家蒙羞。在《万登南部发生的事件》的 小说里, 穆索老爷因他的霸道而受到了人民的反抗, 他认为他所面临的不愉快的问题是他妻子造成的。他 打了妻子并说：“你这个倒霉的女人!” (46页); 此 外, 普拉姆迪亚的布鲁岛笔记也写到这个问题: 日本 帝国主义拐骗妇女, 骗她们说去新加坡或东京受更高 的教育, 事实上是骗她们去当日本士兵的慰安妇。她 们被强奸, 被当作日本士兵的玩具; 她们没有得到法 律的保护。印尼独立后, 这些女性不敢回家, 因为她 们对她们的过去感到差耻, 而且认为她们回家也只 能使自己和家人丢脸。（参考于《军队掌里的年轻处 女》: 13-54 页)

笔者认为普拉姆迪亚女性主义在作品中的表现可以分 成以下几个方面:

\section{（一）父权制是压迫妇女的源头}

普拉姆迪亚在小说里常提到女性的社会地位非 常低, 她们没有自己的主见, 连身体和命运都由父亲 或男人来决定的。普拉姆迪亚认为父权制是压迫女性 的源头。如《人世间》第5章里提到温托索罗姨娘讲 述她被父亲卖掉成为荷兰人的小妾的经历。她的终身 大事都由父亲做主。一旦终身已定, 那么女人全心全 意地侍候那原来并不相识的男人, 侍候他一辈子, 一 直侍候到他死, 或直到他嫌弃她, 把她赶走为止。女 人是别无他路可走。温托索罗姨娘说: “我必须听从 父母的吩咐, 尤其不能违抗我的父亲。我毕竟是个女 儿, 我对父亲无能为力。母亲的眼泪和劝说阻止不了 灾难的发生。世界啊, 我不理解它, 它亦不属于我、连 我自己的身体，也都不归我所有!”

普拉穆迪亚大部分的作品里常指父权制造成女 性的生活不愉快。《万国之子》里提到

苏拉蒂 (温托索罗的侄女)也因为父权制受到压 迫。当他父亲决定要把她送给荷兰人一一普利肯博 时, 她不能反抗, 因为她从小受到的教育是把父亲或 其他男人的话当作圣旨。苏拉蒂本人畏惧父亲。苏 拉蒂的生活乐趣从此消失殆尽。《海女儿》讲述一个 渔民的女儿的故事。她喜欢渔民的生活, 可被逼嫁给 一个不相识的男人, 被送进豪华的房子, 那儿充满了侍 候她的女佣。她对她获得的财产并不愉快, 因为她知 道她富裕的生活是用她的人生的自由换来的, 从此她
失去了自由、失去了她拥有的权利, 如: 失去了说话 和喊叫的权利, 她很清楚, 从此将失去了她愉快地生 活。她把她的新生活描述为她的新生活太多铁线、阻 拦铁手和使她害怕的各种各样的神灵。她把自己比喻 为从鸡群里被抢走的小鸡, 必须单独地生活、不能拥 有朋友, 只能听从命令。她认为这生活好冷淡、好寂 寞啊!

普拉姆迪亚通过他小说里创作的女角色的对话 和感受来表示他对父权制社会的看法。在父权制社会 里, 妇女的地位通常被认为低于男人, 她们没有任何 权利, 连自己的命运、身体都得由男人来支配。普拉 姆迪亚通过小说来表现父权制造成女性的压迫, 使妇 女过着痛苦的生活。

（二）爪哇封建主义是妇女压迫的一个因素

爪哇岛是印尼从古至今的重要政治、文化、艺 术、教育、经济等各个方面的中心，因此印尼在很 多方面都把爪哇民族思想作为各个方面的评价标准， 如女性的贤妻良母的标准、下司对待上司的标准等。 普拉姆迪亚在接受采访的时候也多次批评爪哇封建礼 节, 他通过小说里的人物的对话来表现出作者对爪哇 封建礼节和爪哇封建思想的批评。如《人世间》里的 明克多次对爪哇屈尊爬行的习俗表示批评。他讨厌跍 拜并认为蹃拜是个羞辱的礼节: “趾拜是什么意思 呢? 踠拜即是低三下四, 卑躬屈膝地尊崇祖先和达官 贵人。如果可能, 甚至还要做到头地相接! 啊, 我绝 不能让我的子孙将来再忍受这样的羞辱。”(第133135页)。明克学了欧洲科学以后, 就觉得蹃拜是一个 不符合理智的动作。当他去温托索罗姨娘家做客, 看 到女佣端来可可牛奶时, 并没有像侍候其他土著老爷 那样显得低三下四地躬身弯腰, 甚至还用惊奇的目光 望着明克, 这使明克觉得很新奇, 因为这些情况是在 土著老爷家里决不可能存在着, 女佣在土著老爷家里 除了必须躬身弯腰地走路, 也永远不能抬起头来。明 克想: 如果这世界上没有阶级, 人们可以在别人面前 直着腰走路, 这样的生活该是多么有意思呀! (参考 于《人世间》：第22页）

普拉姆迪亚在他的《海女儿》的作品里很明确 地描述了爪哇封建主义对妇女的压迫, 他也通过作品 里的女主人公的感情变化来说明爪哇封建主义是压迫 妇女的其中一个因素:

《海女儿》里的女佣教海女儿不能大声地说 话, 不能有什么主见, 女人的任务只有侍候男人。海 女儿进入了如此的爪哇封建的家庭常常感到惧怕、发 抖, 她想反抗, 但无能为力。她想起她从前在海边的 生活, 那时她想说什么就说什么, 她可以大声哭, 她 也可以大喊大叫, 没有什么人可以阻止。如今她只能 小声地说话, 不能大叫, 做什么事都自由, 她只能随乡 入俗。以前她还可以把目光向四处看, 如今她只能看 着地, 不能抬头与人相望, 使她不知到底还能看到什么 东西 (19和37页)。海女儿不明白, 心理也觉得很繁 乱, 她想: 难道县大爷比大海还要可怕, 比大海更有权 力吗? 为什么父亲能因为县大爷而逃跑呢? 我父亲从 不怕大海, 但为什他现在逃跑呢? 我也不曾怕过大海, 但为什么我很怕县大爷呢? 为什么? 父亲比县大爷 还要强壮, 而县大爷却是个脸色苍白, 又瘦又脆弱的男 人, 但为什么所有人都怕他呢? (48页)

普拉姆迪亚通过海女儿和其他人对县大爷的恐 惧, 来指明这里的县大爷代表的是爪哇封建主义，并 描述了爪哇封建主义带给女人的心理压迫。爪哇封 建社会里, 人们非常重视社会的阶级。社会地位越高 的人越受人们的尊敬与服从, 社会地位低的人应该尊 
重地位高的人，也应该全心全意服从他。《玻璃屋》 里庞厄玛南也提到爪哇封建阶级的丑唒：“上司责骂 我, 我就责骂我的下属, 下属便责骂他的妻子, 妻子 责骂孩子, 孩子呢? 他就责骂仆人。仆人是人类最低 的阶级。晚上工作了以后她便进入卧室痛哭一场, 但 第二天她还是照常服从上司, 照样工作, 照样挨骂。 她是绝不可能离开上司的。（35页）

普拉姆迪亚也在小说里指出妇女受到爪哇封建 主义思想的压迫。如他在《足迹》里写到明克和他母 亲不同观念的对话。明克用笔反杭资本主义, 他的母 亲知道了后就急勿勿地去编辑部找他, 她很担心她儿 子的安全。她对明克的做法焦急不安, 也认为他何苦 那样做。母亲觉得明克不用为农民命运忧虑。明克告 诉母亲在中国, 人民已经推翻了清王宫, 建立共和 国, 不需要皇帝了。可是他母亲看不起那些华人, 因 为他们不懂爪哇文化: “你是指那些华人的国家吗? 中国算什么? 有什么值得提的? 那些华人不懂爪哇 文化, 没有什么了不起的！她们哪懂我们的礼仪?” (444页)

以上几个情节就是普拉姆迪亚通过小说来描述 爪哇封建主义对女性的身体动作的压迫、心理压迫、 思想压迫。根据普拉姆迪亚作品里的描述, 妇女的身 体动作受到压迫, 她们不能随意行动, 跟男子存在着一 定的区别。她们做什么事都不自由, 不能大声地说 话, 没有自由选择权, 不能有主见, 应该依赖男性, 这种 封建主义的要求使妇女受到心理和思想的压迫。

\section{（三）殖民主义也是压迫妇女的因素}

殖民主义是指一个比较强大的国家对外扩张领 土、建立殖民地的政策, 是资本主义国家采取军事、 政治和经济手段, 占领! 奴役和剥削弱小国家、民族和 落后地区, 将其变为殖民地、半殖民的国家。普拉姆 迪亚在小说里好几次提到女性是国家发达的一种条 件, 如果女性不解放那么国家也不会发达。女性是社 会中受到压迫最多的社会成员, 除了受到家庭的压迫 之外也受到社会的压迫。普拉姆迪亚还通过小说也表 示: 殖民地女性不仅受到父权制和封建主义的压迫, 也受到了殖民主义的压迫, 这种压迫是所有殖民地所 面临的问题。普拉姆迪亚在他的小说里指明: 殖民主 义国家常把殖民地人民视为不文明、贫穷、落后、没 有文化、受到传统束缚、软弱无能。

普拉姆迪亚也通过小说里的西方女性或受到西 方文化影响的女性跟没有受到西方文化影响的女性对 比, 说明西方女性由于具备先进意识因而她们不容易 受男性的压迫, 而印尼女性受到殖民主义的种种限制 和压迫, 变成落后和软弱。《人世间》里的明克对温 托罗索姨娘的看法代表了土著人民对受到西方文化影 响的妇女的思想。明克自从接受西方教育以后, 就觉 得印尼土著人民不如西方人, 他也通过受过西方文化 影响的温托索罗姨娘和其他土著妇女的对比指明西方 教育的作用。明克非常欣赏姨娘, 因为她不仅能讲一 口这么好的荷兰语, 而且更主要的是她在男性客人面 前没有那么繁文裖节。他觉得非常好奇姨娘作为一个 小妾, 怎么能表现得像欧洲妇女那样开明大方（第3 页）。普拉姆迪亚还通过米丽娅姆给明克的信说明西 方人认为他们是最先进的民族, 而殖民地人民都不文 明、落后: “明克, 当荷兰妇女们听到一个爪哇土著妇 女竟能用自己的文字写信时, 人们都惊柁不已。长期 以来, 荷兰妇女都一直认为, 东印度的土著妇女还生活 在石器时代, 仍处在野蛮无知的状态。” ( 《万国之 子》: 第140页)

荷兰殖民政府统治期间, 印尼流行纳妾的习
俗。荷兰男子认为纳妾是一件对他们有利的事, 因为 纳妾是没有法律合约的, 所以他们可以随时放下责任, 抛弃妾和她的孩子们。印尼土著女子成为荷兰殖民 统治者的性工具, 受到了压迫。《人世间》里温托罗 索姨娘多次当姨娘的苦处, 说她是是卖给别人的家 奴, 义务是满足主人的欲望, 什么事情都得顺从她的主 人。她必须随时提防发生这种可能: 主人把她玩够了, 玩淢了, 说不定哪一天会把她和她生下的孩子一起赶 走。因为不是正式婚姻, 生下的子女在土著民中也被 人燋不起 (第94页)。温托索罗姨娘的女儿和明克恋 爱, 可是荷兰殖民政府的法律不承认温托索罗女儿和 明克的恋爱。姨娘很生气, 她说: “他们不把土著 民殊在脚下是不甘心的。在他们看来, 土著民必定有 罪, 欧洲人肯定洁白无瑕（第313页）。温托索罗姨娘 后来在法官面前说: “我原来的名字叫萨妮庚, 地位是 一位拼妇。在我给别当娇妇时, 我生下了安娜丽丝, 仅 仅是因为梅莱玛先生是欧洲人, 就没有指控我与他的 关系。那么, 为什么我女儿与明克先生的关系却成问 题呢? 难道就是由于明克先生是土著民的缘故吗? 对 于其他欧印混血儿的父母, 你们怎么提都不提呢? 在 我与梅莱玛先生之间, 有着奴律办的从属关系, 对于这 一点, 法庭却置若同闻。我的女儿和明克先生真诚相 爱。欧洲人能够用金钱买我这样的上著女人当娇妇, 难道这样买卖比真诚的爱情更合理吗? 倘若欧洲人因 为有钱有势, 就能那样做, 那么为什么土著民的真诚 爱情, 反而却遭到讽刺、嘲笑呢?” (322页) 可是检 察官凶狠地告诉姨娘和明克, 说姨娘的女儿是欧混血 儿, 是印欧混血儿, 她比作为土著人的姨娘和明克的 地位高贵。姨娘非常生气告诉法官人: “ 是谁使我 沦为别人的拼妇的? 是谁逼迫土著妇女给欧洲人作 姨娘的呢? 是你们! 是你们这些被尊为老爷的欧洲 人!”(第323页)

后来普拉姆迪亚也通过明克崇拜西方人到厌恶 他们的思想转变来阐明殖民主义是压迫整个人民 (包 括妇女在内) 的一个因素。普拉姆迪亚通过小说中的 温托索罗和明克言语来表示他对妇女受压迫的思考, 认为妇女除了受父权制和封建主义的压迫之外, 也受 到殖民主义的压迫: “我没有上过学, 孩子, 没有人教 我去崇拜欧洲人。你上了十几年的学。你都学些什 么了呢? 无非还是学那老一套: 学五体投地地崇拜他 们, 崇拜到竟忘了自己是什么人, 忘了自己的家乡。 即使如此, 上学的人还是比较幸运的。至少, 他可以 了解到, 别的民族是怎样用自己特有的方式, 去掠夺 其他民族的财富的。”（第377页）

（四）资本主义也是压迫妇女的其中一个因素 资本主义是以资本家占有生产资料和剥削雇用 劳动者为基础的社会制度。它的基本特征是生产力高 度发展, 鼓励自由的市场经济, 政府对经济的干预尽 量少; 商品生产发展到最高阶段, 成为社会生产普遍 的和统治的形式, 劳动力也变成了商品; 资本家占有 生产资料, 用雇用劳动的方式剥削工人阶级, 生产的目 的是创造利润; 以使用机器的大生产为特征, 生产社 会化同资本主义的私人占有制之间的矛盾构成资本主 义社会的基本矛盾, 这一基本矛盾贯穿于资本主义发 展的始终, 它在经济上具体表现为个别企业生产有组 织和整个社会生产的无政府状态的矛盾, 在政治上表 现为资产阶级和无产阶级的矛盾; 与资本主义生产关 系的统治形式相适应, 资本主义以前的各种上层建筑 被资产阶级的上层建筑所代替, 产生了资产阶级的国 家政权、法律制度和思想体系, 形成包括资本主义生 产方式和与它相适应的上层建筑的社会制度。 
女性的社会地位很低, 但她们是社会的重要成 员。借普拉姆迪亚在小说里的话: 如果一个国家的妇 女受到压迫, 那么那个民族就不能受到别人的尊敬。 妇女是生存、生活、传宗接代、兴旺发达和繁荣茂盛 的象征（参考与《足迹》:第105页; 《人世间》: 第 464页）。恩格斯说过: 社会的进步可以用女性的社 会地位来衡量, 也就是说如果一个国家的女性受到压 迫, 社会就不能进步。普拉姆迪亚也在小说《足迹》 的洪山梅 (中国青年) 和明克的对话里叙述了资本主义 同帝国主义成为压迫人民的因素。洪山梅说：“瓦特 发明蒸汽机, 开辟了英国工业革命的新纪元, 随之产生 了英国帝国主义, 原始资本的积累以及劳动和资本 的分家使有色种族变成英国资本的牛马。”（第202 页）普拉姆迪亚在他的小说里描写了资本主义压迫 妇女的形式。资本主义把妇女当作商品交易：“殖民 主义只对资本家有利, 它们的恶手却弄脏了贵族们的 手, 使贵族们为了获得利益而去压迫平民。”（《玻 璃屋》: 第33页）资本家和殖民政府知道爪哇的贵族 们都为了荣耀和权力而生活, 对爪哇贵族们地位和别 人的尊敬是他们生活中最重要的目的, 他们都不愿意 失去荣耀、地位和权力: “越常跟西方人打交道的职 业, 意思是就越尊贵。西方人是权力的象征, 而权力可 以召唤金钱。”（《人世间》:第251-252页）因此资 本家和殖民政府利用爪哇贵族的弱点去压迫农民或其 他底层人民, 甚至逼百姓把自己的女儿卖给他们。普 拉姆迪亚作品里的温托索洛姨娘和温托索罗侄女一 苏拉蒂就是其中例子, 她们被其父亲当作商品与资本 家进行交易。温托索罗姨娘认为她成为了奴隶, 除了 为丈夫的农场做牛做马, 也必须服侍丈夫。从温托索 罗姨娘和苏拉蒂的角度来看, 她们的家庭是资本主义 制度的受害者, 自己则是资本主义的牺牲品。

\section{（五）种族主义也是压迫女性的因素}

种族主义是一种自我中心的态度, 认为自己所 属的团体, 例如人种、民族或国家, 优越于其他团体。 普拉姆迪亚作品里也提到种族主义的危害。它诱使人 们相信, 被认为先进的民族可以随便对待那个比它落 后的民族。这种压迫是包括女性在内的。普拉姆迪亚 作品里也提到此观念。如: 《人世间》里的温托索 罗姨娘给她女儿讲她小时候的故事时, 提到种族区别, 她告诉女儿, 根据习俗一位守规矩的姑娘是不能抬起 头, 睁开眼去看一位陌生的男宾的。如果客人是位白 人, 那就更不合适了（第89页）。温托索罗姨娘觉得 消除种族区别可以使她和她丈夫平等, 殖民主义和资 本主义的灌输, 大家都认为白人优越于有色皮肤的民 族。温托索罗真盼望着可以与白人平等, 因此她模仿 荷兰妇女杂志所写的妇女形象。实践了一段时间后, 她便问丈夫她是否像西方女人, 她丈夫认为她不需要 改变成一位荷兰妇女, 也没有必要成为荷兰妇女。他 认为姨娘比那些西方妇女更聪明、更能干, 比她们任 何人都强（第100页）

普拉姆迪亚也通过温托索罗姨娘的儿子 (罗伯 特) 提到种族区别的问题, 罗伯特认为自己所属的种族 高于他母亲的种族, 因此他母亲也应该服从他。在罗 伯特看来, 至高无上的事情就是当一名欧洲人, 所有 的土著民都必须屈服他。（《人世间》：第71页） 此外, 温托索罗姨娘的丈夫的合法儿子一一毛里茨. 梅莱玛也看不起温托索罗姨娘, 因为他认为温托索罗 姨娘是地位下贱的女人, 她勾引了他父亲。除此之 外, 他认为温托索罗姨娘是有色土著民族而且不是基 督教徒, 比基督教的白人种族地位还要低。毛里茨. 梅莱玛的说的话和态度打击了温托索罗姨娘。她崇
拜的欧洲文明却高高在上, 欺负了她, 侮辱了她的种 族、社会地位、宗教和孩子。

普拉姆迪亚通过了小说中的一些情景告诉读 者: 种族主义确实是压迫人民思想 (包括女性) 的一种 工具。自称高贵的民族将欺负它认为低于自己的民 族, 并逼迫低于它的民族承认它的种族地位。其后果 可以从小说里的梅莱玛先生对温托索罗姨娘模仿西方 女性的行为的话语看出来: 梅莱玛先生认为温托索罗 姨娘可以把西方的好处学过来, 但不需要全模仿西方 女性的特征, 需要保持她本人的特征。另外, 其后果也 可以从温托索罗姨娘批评明克的话语看出来: 温托索 罗批评明克因为崇拜白种族而忘了他本身的种族。 参考《人世间》：第377页）

\section{（六）阶级也是压迫女性的因素}

女性在各个方面都受到压迫, 一个民族受到压 迫的同时, 女性也受到压迫。其实是因为父权制也好, 封建主义! 殖民主义、资本主义也好, 这都是阶级的压 迫。普拉姆迪亚小说里也表示了阶级压迫女性的观 点, 如: 《玻璃屋》里庞厄玛南说: “上司责骂我, 我就责骂我的下属, 下属便责骂他的妻子, 妻子责骂 孩子, 孩子呢? 他就责骂仆人。仆人是人类最低的阶 级。晚上工作了以后她便进入卧室痛哭一场。

姨娘们地位很低, 不是荷兰人的合法妻子, 因此 没有受到法律保护。普拉姆迪亚通过小说里明克的想 法来表示了社会上各个阶层的人民都歧视姨娘们。明 克想: “看来谁都了解那些姨娘们家里的道德情况。 她们下流, 淫乱, 无文明可言。她们呀, 都是妓女, 是没有人格的人, 生来就注定要堕入泥潭, 被人遗弃 的。社会上的每个阶层、每个民族, 无论是土著民、 欧洲人, 还是中国人、阿拉伯人, 没有一个是不谴责她 们的家庭的。”（《人世间》：第53页）

（七）普拉姆迪亚的作品里提到女性解放首先就是妇 女要受教育, 接着妇女应该向所有压迫她们的势力作 斗争。最重要的是: 妇女应该先勇敢解放自己、参与 社团, 通过社团的团结奋斗才能把她们从压迫中解放 出来。

普拉姆迪亚非常注重科学对人类的影响。他的 四部曲的最前面的一段就写着明克对科学的体会：“ 在我这一生中, 在我这短暂的一生中, 我已经体会到科 学给我带来了无限美好的前景。”; 在《人世间》小 说里, 明克多次为温托索罗姨娘的知识而惊叹不已, 如: 他为温托索罗姨娘能讲一口学院式的、发音十分 标准的荷兰语感到非常钦佩（第20页）。当时殖民主 义制度压迫人民，不许人民受教育，只有得到特权的 贵族孩子们才能获得荷兰教育。一个土著女子会说很 好的荷兰语是一件不同寻常的事。当明克知道了温托 索罗姨娘阅读了很多欧洲书籍也感到很惊讶, 这使他 更敬佩姨娘，认为她是一生中见过最有学问的土著妇 女 (第204页)。明克也通过与他母亲的对比, 说明 温托索罗姨娘的特点。他认为温托索罗姨娘受过教育 后, 是个非常先进的女人, 言语非常开放; 而他母亲却 受到封建主义的压迫, 视野狭窄, 将世界上所发生的事 当成美丽的神话, 跟母亲对比, 温托索罗姨娘相对来 说是个妇女解放的形象, 原因是她学习不辍, 追求先 进的科学知识。

妇女也应该向所有压迫她们的势力做斗争。普 拉姆迪亚《人世间》的小说里对此问题叙述得非常 清楚。小说里讲到荷兰政府法院不承认温托索罗姨娘 是安娜丽丝的母亲, 它们也不承认安娜丽丝和明克的 婚礼。这是因为明克是土著民, 而安娜丽丝是混血儿 
的缘故。由于在法律上温托索罗没有抚养安娜丽丝的 权利, 因此法院逼安娜丽丝回荷兰, 使温托索罗姨娘 和她的女儿受到隔离。可是温托索罗姨娘不屈服, 她 说: “明克, 我们要进行反杭。你有胆量吗, 孩子? 尽管没有法律专家, 我们也要反抗, 我们将成为反 杭白人法庭的第一批土著民, 难道这不是一种繁荣 吗？”（第372-373）他们明白, 自己的官司打不赢, 但他们有责任进行反杭, 以维护自己的权利, 一直到 无法反抗为止。虽然后来他们的反抗失败, 但温托索 罗说: “我们已经反杭了, 孩子, 我的孩子! 我们已经 尽了最大的努力, 做了最体面的反杭。”（第402页）

普拉姆迪亚《万国之子》的小说里也提到名叫 苏拉蒂的女子 (温托索罗姨娘的侄女), 她受到父权制 和资本主义的压迫。她父亲把她卖去当一个荷兰资本 家的小妾。她不想自愿当小妾, 不想被成低贱! 没有 价值的妇女。她知道她不能反抗父亲, 但也不愿不反 抗, 最后她决定用其他的方法来反抗, 她故意让那个 荷兰人传上传染病, 因病而故。

普拉姆迪亚小说里还提到妇女的其它反抗方 式, 如扎巴拉小姐用笔墨反抗封建主义, 温托索罗姨 娘用追求学问、劳动和话语的方法来反抗社会压迫。 普拉姆迪亚小说里提到: 需要团结起来, 先解放自己。 普拉姆迪亚通过他小说的人物对话描述了女性解放就 是全体女性努力的结果, 也是内心激烈斗争的成果。

(八) 普拉姆迪亚非常赞成妇女参加劳动, 小说里也 可以体现出参加劳动是一种解放妇女的形式, 普拉姆 迪亚的四部曲里有很多地方称赞参加劳动的妇女

例如，明克第一次参观温托索罗姨娘农场的时 候, 看到很多妇女参加劳动, 心里不禁地呼唤: “啊, 妇女！妇女也能参加农场工作！妇女也能穿白粗布工 作服！这些农村妇女, 也都穿起工作服来啦！她们不 再在自家的厨房围着锅台转啦！”（《人世间》, 第 29页）后来当明克知道安娜丽丝是工长的时候, 更加 惊讶和钦佩。他没有想到娇媚稚气的安娜丽丝却是男 工和女工都必须听从她的吩咐的工长。他也想象不到 那些农村妇女竟然离开了锅台, 穿上了工作服, 和男 工们混合在一起, 到别人的农场去寻找生计。明克更 不能相信温托索罗姨娘也是个能干的女子, 可以处理 行政事务、跟银行打交道。

在小说《足迹》里普拉姆迪亚通过特. 哈尔 记者和明克的讨论, 进一步肯定了 “劳动可以解放女 性” 的观点。特. 哈尔说: “只有自由劳动能够提高 土著民的身份和价值, 而强迫命令就使他们

愚昧。只有自由劳动才能把被遗忘和被排挤的 科学和知识还给他们。自由劳动将使他们摆脱对神的 恐惧, 不怕警察, 也不怕东印度公司的雇佣兵, 只有这 样才产生出真正的土著民来。” (《足迹》: 第24页)

如果从以上关于劳动的观点来看, 温托索罗姨 娘是普拉姆迪亚所塑造的最理想的代表形象。温托索 罗说过: “自食其力的人是幸福的。因为自己的事业 成功而感到快乐, 是自己的苦心经营促使了事业的发 展。” (《人世间》: 第41页) 温托索罗姨娘也说, 她学到的所有知识和劳动提高了她的身价和价值。 她证明出劳动使自己不依靠任何男子, 受到人们的尊 敬。

\section{（九）普拉姆迪亚不赞成 “一夫多妻” 制}

普拉姆迪亚小说里创造出的女性都表现出反对 一夫多制的倾向, 如四部曲里提到的扎巴拉小姐非常 厌恶男子纳妾, 她认为这是一个不尊敬妇女的行为; 当明克在街头听到一个妇女为她丈夫纳妾的问题与丈
夫争吵, 他就想: 这样的妇女生活似如地狱, 难道生活 就要如此吗? 这样的生活又有什么意思? ; 小说里的 明克也多次表示他不想娶几个小妾, 他想到他祖母的 话: 娶两个以上妻子的男人没有一个不是骗子。不管 他自己愿意不愿意, 肯定都是骗子。(《人世间》: 第227页)

\section{（十）男女平等就是女性和男性都可以享有同样的权 利}

普拉姆迪亚小说里, 所谓的男女平等就是女性 和男性可以享有同样的权利, 如工作权、表决权、同 酬权、受教育权、参政权等。他们共同努力, 占有同 等的社会地位。妇女应该有权得到与男性同等的教育 和工作机会, 应该有权发表她们的意见。这可从《人 世间》里的明克敬佩温托索罗姨娘的原因看得出来。 明克认为姨娘可真不是一位普普通通的姨娘。她在一 位荷兰高中的洋学生面前, 看不出有一点自卑感。她 敢于发表自己的意见。她充分意识到自己的力量 (第 75页）; 此外从马赫达. 皮特斯对明克的对话也看得 出来普拉姆迪亚有关男女平等的观念。马赫达. 皮特 斯认为温托索罗姨娘身上最使人钦佩的长处是勇于表 明自己的见解, 即使这种见解未必正确, 她不怕出错, 白折不挠, 有胆量从自己的错误中学习 (第262页) ; 从四部曲的明克和扎巴拉姑娘的思想, 也可以看出 普拉姆迪亚所谓的男女平等的含义是地位平等。明克 很羡慕荷兰人夫妻平等, 丈夫没有把他妻子当作奴 仆; 而妻子也没有把自己当作丈夫的奴仆。明克认为 这样的婚姻是多么美妙啊! 可是明克也认为这样的妇 女从印尼土著民族里是寻找不到的。可是, 对扎巴拉 姑娘来说, 她不同意西方人的女性解放, 她认为男性不 是女性的敌人, 而是女性的合作伙伴。女性和男性需 要得到相同的权利才能平等, 因为她认为每个多余的 权利就是压迫。（《足迹》: 第353页）

\section{普拉姆迪亚女性主义的流派}

通过阅读普拉姆迪亚的一些作品, 笔者体会到 普拉姆迪亚的女性主义非常丰富。他不仅把女性受压 迫的因素看为纯粹的父权制, 而且多方面地揭示了它 的社会根源。根据普拉姆迪亚在小说中所表达的观 点, 笔者认为普拉姆迪亚的女性主义偏向后殖民女性 主义和社会主义女性主义。

\section{（1）后殖民女性主义}

后殖民女性主义在 20 世纪 80 年代后才蔚为风 潮, 这并不是说以往无此类的论述, 而是反映出白人 女性学者在传统权力架构中的弱势地位。女性虽然在 各种文化中都有受压迫的情况, 但她们所受压迫的形 式是不同的。有的女性群体认为女性除了在性别上受 压迫外, 也受到种族、民族的压迫。有色人种女性与 第三世界的女性主义由此产生。1983年沃克批评过去 的女性流派, 认为它们关注的问题是西方白人女性所 面临的问题, 忽略了第三世界女性、下层女性和有色 人种所面临和关注的问题。后殖民女性主义认为那些 女性主义流派忽略了男女性别以外的压迫, 忽略了经 济剥削、政治问题; 她们认为殖民压迫才是问题的关 键词。后殖民女性主义拒绝将女性的压迫问题纯粹归 结为父权压迫。们认为: 第一世界白人女性主义占全 球女性主义重要地位, 很少考虑其他种族、阶级女性 的问题。莫汉蒂 $(C \cdot T \cdot$ Mohanty) 指出, 西方女性主义 者在提到 “妇女” 这个范畴的时候, 不约而同地把它 看作一个先验的、统一的, 有着一致利益和欲望的整 
体, 而有意无意地忽略了它内部包含的阶级、种族、 文化等差异。她们表述第三世界妇女受压迫的特征 时, 她便加上第三世界的特征, 而这第三世界的特征 是 “不发达”, 因此第三世界的女性的形象便塑造为 贫穷的、落后的、没有文化、受到传统束缚的、家庭 趋向的、没有权利意识的、宗教趋向的、依赖性的、 软弱无能的等等; 与之相对立的, 西方女性主义者认 为西方女性是受过教育的、有文化的、文明的、具有 权利意识的、能够主宰自己的命运的、前进的。后殖 民女性主义也认为男性不一定是女性的敌人, 而是携 手共事的同志。后殖民主义女性主义强调, 女人之间 因种族、阶级、文化等因素导致的差异, 必须被纳入 女性议题来探讨, 不可只强调性别认同, 忽略种族歧 视、经济和政治、殖民主义和帝国主义等相关因素。

根据以上的理解, 普拉姆迪亚小说里的女性观 点真的是偏向于后殖民主义女性主义, 因为他认为女 性受压迫不是纯粹因为父权制，也有种族、民族、阶 级、政治上的压迫。小说里揭露了荷兰殖民主义制度 对人民尤其是对女性的压迫。小说里也可以看出: 由 于荷兰殖民主义的影响, 西方白族女性 (以及所有西方 人) 都自称或被称为前进的、受教育的、有文化的、 文明的、具有权利意识的; 而印尼土著女性 (以及土 著民) 却被认为是落后的、贫穷的、受到传统束缚 的、没有权利意识的、宗教取向的、依赖性的、软弱 无能的。四部曲里的明克接受西方教育以后就觉得西 方女性在任何方面都比土著女性先进和有文化, 他没 有看到这个 “落后、不文明” 等特征正因为当时政治 上的压迫, 亦即殖民主义的压迫。后来温托索罗姨娘 代表土著女性指出: 正是殖民主义思想压迫了土著女 性、造成了种族歧视。普拉姆迪亚的小说也认为, 女 性首先要先解放自己、团结起来, 勇敢地向所有压迫 他们的因素开战。普拉姆迪亚也通过小说里的扎巴拉 小姐的看法, 把男女平等列为男性和女性互相协助, 享有相同的权利” 男性不是女性的敌人, 而是携力共 事的合作伙伴。

\section{（2）社会主义女性主义}

马克思主义关于物质决定精神! 经济基础决定 上层建筑的思想对女性主义有很大的影响, 成为社会 主义女性主义研究妇女问题的一个基本理论依据。社 会主义女性主义认为, 把 “阶级” 仅用来区分与生产 资料有关的不同社会群体过于狭窄, 因为女性也是一 个阶级, 认为女性摆脱压迫的道路就是克服女性的异 化和消除劳动的性别分工, 它最终的目标是使社会上 男女阶级的划分归于消失。社会女性主义认为女性在 生活的一切方面系统地处于不利地位, 这不是个人的 能力原因造成的, 而是历史和社会原因造成的, 有的甚 至直接指出妇女受压迫起源于私有财产制的经济结 构, 并认为阶级压迫是更基本的压迫, 所以男权压迫同 阶级同样重要, 二者都是压迫妇的女形式, 因此改变妇 女被压迫的处境或改变女性的不利地位不能仅仅靠个 人的努力, 而是要为女性争取特别的保护性立法, 以及 各种救助弱势群体的特殊措施, 以此争得同男子平等 的地位。社会主义的一个主要现实斗争要求就是男女 同工同酬。社会主义女性主义认为, 在资本主义社会 中, 生产、生育、性和儿童社会教化在家庭中结合在 一起, 相互依存, 是女性受压迫的原因。米歇尔在《妇 女: 最漫长的革命》里提到了此问题。她向社会呼唤, 说: “只有改变紧密结合成统一体的生产、生育、性 和儿童的社会化问题, 妇女才能真正获得解放。她还 指出, 在这四个方面问题, 经济因素 (生产) 仍然是主要 的, 但必须伴有同其他三个因素相一致的政策, 这些政
策在直接行动的特殊关头所起到的作用可能超过经济 因素。从以上的观点来看, 社会女性主义主张妇女必 须参与阶级斗争和社会主义革命, 推翻资本主义私有 财产制度并将男权制的心理加以转变; 它主张妇女进 入劳

动力市场, 与男工同工同酬, 也消除劳动的性别 分工, 使男女阶级的划分归于消失; 它也主张把家务 劳动变成公共生产, 使家务劳动社会化, 使妇女无酬劳 动变成有酬劳动, 从而实现妇女的劳动价值及人格价 值, 这样才能实现男女平等, 使妇女真正解放。（啜大 鹏, 2001:318-320)

笔者认为普拉姆迪亚小说的女性观点也偏向于 社会主义女性主义。他的四部曲提到爪哇社会的四 个阶级: 婆罗门、刹旁利、吠舍和首陀罗。这些印度 阶级传进爪哇, 为爪哇社会所运用” 普拉姆迪亚的四 部曲和其它小说里提到爪哇阶级对人民的压迫, 属于 低阶级的人民无论什么原因都应该听从和服从属于 高阶级的人民; 属于低阶级的人民在社会里无论有 多么能干, 也不能超过属于高阶级的人民。妇人也是 个阶级。普拉姆迪亚也通过他的小说叙述了这一点, 不同阶级的妇女有不同阶级的行为和态度, 如：《海女 儿》提到贵族妇女 (刹旁利) 看不起吠舍级妇女, 她们 不能与吠舍级的妇女沟通, 社会也指定了刹旁利级的 妇女的任务命令低阶级的妇女; 而低阶级的妇女的任 务是服从高阶级的妇女。普拉姆迪亚小说里除了叙述 了妇女之间的阶级压迫, 他也叙述了男女之间的阶级 压迫, 因为无论那个女子有很高阶级, 她的阶级也比男 子低。四部曲里的明克厌恶爪哇的社会阶级和语言阶 级, 认为阶级是造成爪哇人愚昧无能的因素, 也是因为 阶级爪哇人反抗不了殖民主义和资本主义, 因此明克 一直表现出反抗爪哇阶级。《海女儿》里的海女儿意 识到阶级的压迫, 她想反抗但无能为力。除此之外, 普 拉姆迪亚指出在资本主义社会里, 家庭是妇女最常受 到压迫的领域。生儿育女、维持家庭是妇女的天性, 她在家庭里的无酬劳动 (如: 做饭、照顾孩子等) 被社 会认为是女性应该做的事情。这些家庭压迫是与资本 主义压迫人民相似的。四部曲里的温托索罗姨娘就是 受资本主义制度压迫的妇女代表。她在家庭受到压 迫, 做了所有女性应该做的任务, 但社会却不承认她所 做的; 她也要为丈夫打扮, 一直要注意自己的仪表, 认 为不注意仪表的妇女是无能; 她也没有性自由权、对 自己的身体没有任何权力, 埋没了温托索罗姨娘的潜 能。这些家庭压迫是与资本主义压迫人民的形式相似 的。温托索罗姨娘进入劳动市场后, 就能发挥她的能 力, 享有与男人相同的工作权力, 成为一个世人敬佩的 女人。不过, 虽然温托索罗已经解放自己, 但是她还脱 离不了社会里的一些制度, 她还是被那些制度压迫。 明克作为先进的知识分子开始也拥有压迫妇女的思 想, 认为妇女的地位低, 但是通过解放他自己的思想, 摆脱了父权制, 对女性的想法和态度就有所改变。普 拉姆迪亚通过温托索罗姨娘和明克来表示男性并不是 女性的敌人, 也并不是女性和男性的生理区别引起了 社会对女性的压迫，而是社会制度导致女性的压迫。 普拉姆迪亚通过他小说里的一些情节、人物的心理矛 盾和人物对话来表现出社会制度和阶级观是社会和历 史造成的, 因此推翻社会制度和阶级、改变社会男权 制的社会心理可以使男女平等。从以上的普拉姆迪亚 小说的观点看, 笔者认为他的女性主义偏向于社会主 义女性主义。 
女性主义是泛指妇女要求平等权利的社会思 潮, 是妇女在寻求自我解放过程中, 认识了世界、认识 了自我、认识了两性关系的一种认识成果和思想结 晶。女性主义的产生与父系社会有密切的联系。世界 上大多数文化都包含了男人胜于女人、男人比女人重 要的主导观念, 因此女人被看成为男人的奴隶、生孩 子的工具、满足男人性爱的器血, 成为政治上的牺

牲品、经济上的商品。她们没有社会地位和权 利。印尼也是如此, 女人的社会地位低于男性, 甚至 常被认为是男性的奴隶。女性主义在印尼的传播, 与 印尼成为西方殖民地及西方资本主义在印尼的发展背 景有密切的关系。随着西方国家和印尼文化! 经济及 政治的交流, , 西方女性主义的思想也渐渐地融入了 印尼社会, 启迪了印尼女性的思想, 使她们首次思考自 己在印尼社会中的地位, 要求男女在社会上包括受教 育、参政、就业等方面的平等, 主张妇女解放。

笔者把普拉姆迪亚在作品中所表达的女性主义 观点归纳为以下几点: 父权制是压迫妇女的源头; 封 建主义、殖民主义、资本主义、种族主义、阶级也是 压迫女性的因素; 女性解放就是妇女首先要受教育, 接着妇女应该向所有压迫她们的势力作斗争，但最重 要的, 妇女应该先勇敢解放自己! 参与社团, 通过社团 的团结奋斗才能把她们从压迫中解放出来; 妇女应该 进入市场上的劳动, 因为市场上的劳动是解放妇女的 形式; 反对 “一夫多妻” 制; 男女平等就是女性和男 性都可以享有同样的权利。笔者体会到普拉姆迪亚作 品里的女性主义观点非常丰富, 他不是把女性受压迫 的压迫看为纯粹的父权制, 而且多方面寻找其根源, 并叙述了妇女解放和男女平等的形式。根据普拉姆迪 亚在小说里对女性问题的一些叙述, 笔者认为普拉姆 迪亚的女性主义比较偏向后殖民女性主义和社会主义 女性主义。笔者认为, 所谓的男女平等不是女性和男 性在任何方面都是一样的, 而是女性可以享有与男性 相同的权利” 解放妇女不能靠个人的力量, 它应该靠 全体社会成员的努力和合作。笔者很赞同普拉姆迪亚 的女性主义, 认为妇女解放就是妇女除了应该有机会 与男性受到同样的教育外, 也可以做与男性同样的工 作, 同工同酬, 妇女应该团结起来, 勇敢地向压迫她们 的社会制度奋斗, 但最重要的还是思想上的改变, 因为 世界上最可怕的压迫并不是身体上的压迫，而是思想 上的压迫, 因此改变所有社会对男女平等的看法才是 最关键的。笔者对普拉姆迪亚思考女性问题的敏锐感 到敬佩。他已经看到种族主义和阶级对妇女的压迫, 目前的印尼女性主义正在往这条路上走。印尼女性 主义正为男女阶级的压迫而开战, 主张消除宗教对她 们身体的压迫 (争取穿着自由权、性自由权, 注重女 性身体的快乐和感受性，反对女性身体快乐的压抑） , 主张妇女进入劳动市场, 与男性同工同酬, 主张消 除资本主义的压迫 (如家庭暴乱、印尼家庭里的主仆 的压迫、妇女在劳动市场上所受到的暴乱和不公平对 待等), 主张妇女争取与男性相同的权利 (如工作机会 权、财产权、政治权、表决权)。笔者相信, 通过印尼 女性主义的斗争, 将减少印尼妇女的压迫。笔者认为, 印尼女性主义的前景就是将把女性主义和宗教意识结 合在一起, 寻找适合印尼社会的女性解放之路。
啜大鹏. (2001). 女性学. 北京: 中国文联出版社

李银河. (2007). 妇女:最漫长的革命 (当代西方女性 主义理论精选).北京: 中国妇女出版社

马新国. (2006). 西方文论史. 北京: 高等教育出版社 杨春时、余兆平、黄鸣奋. (2003). 文学概论. 北京: 人民文学出版社

吴中杰. (2002). 文艺学导论. 上海: 复旦大学出版社 普拉姆迪亚. 阿南达. 杜尔. (1982). 人世间. 北京: 北 京大学出版社

普拉姆迪亚. 阿南达. 杜尔. (1983). 万国之子. 北京： 北京大学出版社

普拉姆迪亚. 阿南达. 杜尔. (1989). 足迹. 北京: 北京 大学出版社

李学民、黄昆章。（2005）。印尼华侨史(古代至1949 年）.广州州: 东高等教育出版社

川罗钢、亚莉. (2001)。种族、性别与文化的政 治一一后殖民女性主义的理论与批评实践.

北京: 北京师范大学学报第200001期号第101页

女性主义。 (2008).年1月2日下载于 http://book.sina.com.cn/nzt/sex/1110349762 nvxingzhuyi/index.shtml

“马克思主义女性主义批评的理论形成的逻辑延 伸”。(2007)。年3月3日下载于

http://www.gy16.com/fanwei/article/2005-1030/3435-1.htm

“后殖民主义”。(2008)。年3月15日下载于 http:// baike.baidu.com/view/777895.html

“资本主义”。(2008) 年3月7日下载于 http://baike. baidu.com/view/163.html

Arivia, G. (2006). Feminisme: Sebuah Kata Hati. Jakarta: Kompas.

Bandel, K. Perempuan Jawa dalam Cerpen Pramoedya Ananta Toer dan Umar Kayam. Jurnal Cerpen Indonesia, Ed. 8.

Gorki, M. (2002). Ibunda. Jakarta: Kayanamitra.

Mulyowati, E. (2007). Analisis Tokoh Midah dalam Midah, si Manis Bergigi Emas. Jakarta: FIB UI.

Pane, A. (2005). Habis Gelap Terbitlah Terang. Jakarta: Balai Pustaka.

Ratna, N. K. (2008). Postkolonialisme Indonesia. Yogyakarta: Pustaka Pelajar.

Rizal,J. J. (2007). Jejak Perempuan dalam Historiografi Indonesia. Jurnal Perempuan, Ed. 52.

Sugihastuti \& Saptiawan, I. H. (2007). Gender \& Inferioritas Perempuan. Yogyakarta: Pustaka Pelajar.

Toer, P. A. (2005). Bumi Manusia. Jakarta: Lentera Dipantara.

Toer, P. A. (2007). Anak Semua Bangsa, Jakarta: Lentera Dipantara.

Toer, P. A. (2006). Jejak Langkah, Jakarta: Lentera Dipantara.

Toer, P. A. (2006). Rumah Kaca. Jakarta: Lentera Dipantara.

Toer, P. A. (2007). Gadis Pantai. Jakarta: Lentera Dipantara.

Toer, P. A. (2006). Midah: Si Manis Bergigi Emas. Jakarta: Lentera Dipantara.

Toer, P. A. (2007). Sekali Peristiwa di Banten Selatan. Jakarta: Lentera Dipantara. 
Toer, P. A. (2007). Panggil Aku Kartini Saja. Jakarta: Lentera Dipantara.

Toer, P. A. (2003). Larasati. Jakarta: Lentera Dipantara.

Tong, R. P. (2006). Feminist Thought. Yogyakarta: Jalasutra.

Perspektif Perempuan. Diakses dari http:// w w w / jurna l perempuan. com/y j p . jpo/?act=perspektif\% $\%$ C-36\%7CX pada tanggal 28 Febuari 2008 